\title{
Application of technical and economic analysis in the selection of technical solution in the enterprise
}

\author{
Jianbin Hang, Rui Miao*, Wanchun Yang, Zhaoyi Zhang \\ School of Mechanical Engineering, Shanghai Jiao Tong University, Shanghai, China \\ *miaorui@sjtu.edu.cn
}

Keywords: Technical and economic analysis, comparison of plans, comprehensive evaluation

\begin{abstract}
In view of the problem happened nowadays that the deviation found in the selection of technical solution in the enterprise, on the basis of analyzing the characteristic, this article proposed the solution by technical and economic analysis method, introduced the procedure how to use this method in detail and verified by a case study of a manufacturing company for example. The results show that the application of technical and economic analysis method can provide a scientific basis for the enterprise to formulate and choose technology solutions, which means great significance for the enterprise to invest and make strategic decision.
\end{abstract}

\section{INTRODUCTION}

With the rapid development of modern science and technology and with the increasingly rich management experience, people can use more and more kinds of technical solutions to achieve the same purpose and meet the same needs, in the meantime, people need to choose the best from these technical solutions. In the human production and life practice, regardless of the state, the enterprises or the individuals, will face the problem that need to choose from many different technical solutions which can be substituted for each other. This is a very important theoretical and practical problem how to choose and which standard should be undertaken to choose. For the enterprise, in the environment that the market competition is very cruel, the choice of technical solutions can not only focus on the technical advancement, but also focus on the applicability of the technology, the advanced technology does not necessarily meet the needs of the actual concrete. Some technology is advanced and feasible in itself, but in the specific economic environment, due to the resource conditions, market demand, the influence of the development of related industries and some other conditions, it will not be applicable. If the engineering and technical personnel don't meet the needs of the market and the cost of production, products will be uncompetitive and can't achieve their values, manufacturer of the products will not survive. At present, this kind of enterprise is very common. To avoid this situation, it's necessary for the enterprise to use the technical and economic analysis method to guide the choice of technical solutions. Technical and economic analysis is a kind of method that calculates, analyses, compares and demonstrates the feasibility of technical and economical in the technical solution which is prepared to be carried out in the enterprise, to make the best use of the technical resources and obtain the best economic effect [1]. Technical and economic analysis can help the enterprise to deal with the relationship between advanced technology and economic rationality, to achieve as much as possible with the least social labor consumption, to achieve the best combination of technology and economic rationality as far as possible.

\section{Procedure of TechnicAl AND ECONOMiC ANALYSIS IN THE ENTERPRISE}

The technical and economic analysis method has a very wide range of applications, which not only involves the study of the economic effect of the whole national economy, but also studies the economic effect of a certain enterprise, a project or a scientific research project .Enterprise, as an economic entity, will encounter all kinds of technical decision-making problems in the production and business activities, therefore to master the technical and economic analysis method is very important.Generally speaking, application of technical and economic analysis method to solve the 
actual problems in the enterprise including six steps: proposing the question, setting the target, designing the alternatives, analyzing qualitatively and quantitatively, evaluating comprehensively, providing the decision-making [1]. Proposing the question is to find a technical scheme selection problem happened in the manufacturing process and management process in the enterprise as the research object, such as problems on external investment, expansion and technical transformation, optimization of product structure, perfect sales channel problems, etc.; Setting the target is to make clear the final result through the technical and economic analysis, such as reducing the costs, improving market share, increasing sales revenue, etc.; Designing the alternatives is to develop multiple alternatives according to the actual technology to solve economic problems and to achieve the goal; Analyzing qualitatively and quantitatively is to carry out the technical analysis first then the economic analysis for the various alternatives, by using qualitative and quantitative methods, to get the analysis results; Evaluating comprehensively is to analyze comprehensively the results of technical analysis and economic analysis then make the comprehensive evaluation, to determine the optimal solution;Providing the decision-making is to recommend the selected scheme to the relevant decision-making departments, form a closed loop.

\section{ApPLication CASE}

There is one company which is a professional power station equipment manufacturer, producing a heat exchanger equipment, which belongs to the high pressure vessel, used in the high temperature steam condition, so the design temperature is very high, up to $545^{\circ} \mathrm{C}$, the materials which can be chosen as the shell of the pressure vessel is very few in this design temperature. It is required to find a most appropriate technical solution, which can not only meet the performance requirements of the product, but also get the lowest cost. The technical and economic analysis method can help to solve this problem.

\section{A. Technical analysis and comparison}

Design the alternatives at first. The materials except alloy steel materials can be excluded first for preliminary consideration on the cost. According to the pressure vessel standard [2], in this design temperature, there are only five optional alloy steel materials: SA-387Gr91, 15CrMo, 12Cr1MoV, $12 \mathrm{Cr} 2 \mathrm{Mo} 1$ and $12 \mathrm{Cr} 2 \mathrm{Mo} 1 \mathrm{~V}$, which can be determined as the alternatives. Before carrying out the technical analysis and comparison for the alternatives, technical index evaluation system should be established first. Technical evaluation index can be divided into two levels, the first layer index is design and manufacturing ability, design ability can be divided into allowable stress, material thickness and high Temperature performance, they are the secondary indexes. Manufacturing ability can also be divided into two secondary indexes: plastic deformation and the welding performance. The allowable stress refers to the maximum stress value that the parts or components can bear in the mechanical design or the engineering structures design. The higher the material allowable stress, the higher the product safety performance; The material thickness refers to the minimum shell thickness that allowed in the design condition, the smaller the thickness, the lighter weight the equipment is, more optimized the technique is. High temperature performance refers to the ability of the material that can suffer under high temperature stress for a long time to resist creep rupture, fracture, relaxation, oxidation, corrosion, thermal fatigue and creep phenomenon, the better high temperature performance, the better the performance of products; Plastic deformation refers to is the ability of materials that can be steadily permanent deformation under the action of external force but not destroy its integrity, the better plastic deformation, the easier mid-cooling processing forming in the manufacturing process. Welding performance refers to the difficult degree that materials can get good welded joint in the adoption of a certain welding process including the welding method, welding material, welding procedure and welding conditions. The better welding performance of materials, the easier welding forming in the manufacturing process.

After technical indicators are established, technical feasibility analysis will be carried out for the alternatives at first, it results that $15 \mathrm{CrMo}$ should be excluded because it is not technically feasible 
for major defects in high temperature performance. The rest of the four technical solutions sorts from high to low sequence in the following table according to the technical feasibility analysis results:

TABLE I. TECHNICAL FEASIBILITY ANALYSIS RESULTS SORTING TABLE

\begin{tabular}{|c|c|c|c|c|c|}
\hline $\begin{array}{l}\text { Solution } \\
\text { / Index }\end{array}$ & Allowable stress & $\begin{array}{l}\text { Material } \\
\text { thickness }\end{array}$ & $\begin{array}{l}\text { High temper } \\
\text { performance }\end{array}$ & $\begin{array}{l}\text { ePlastic } \\
\text { deformation }\end{array}$ & $\begin{array}{l}\text { Welding } \\
\text { perform } \\
\text { ance }\end{array}$ \\
\hline SA-387Gr91 & 1 & 1 & 1 & 3 & 3 \\
\hline 12Cr2Mo1V & 2 & 2 & 2 & 4 & 4 \\
\hline $12 \mathrm{Cr} 1 \mathrm{MoV}$ & 3 & 3 & 3 & 1 & 1 \\
\hline 12Cr2Mo1 & 4 & 4 & 4 & 2 & 2 \\
\hline
\end{tabular}

As seen from above table, the four kinds of plans on the five technical indicators have no absolute advantage, it is impossible to find directly the optimal plan. So the expert scoring method combined with weighted calculation method can be used to quantitative evaluation on technical solutions [3]. It is necessary to determine the weight of each technical index distribution at first, the credibility of evaluation results will not be guaranteed until the weights are determined reasonably. These are many ways to determine the weights, mainly divided into subjective weighting method and objective weighting method. It is more applicable for enterprise to use the subjective weighting method and Delphi method can be used as a kind of subjective weighting method [3].Technical evaluation index weights allocation table is shown TABLE II below. After this, experts are invited to score, the results are shown TABLE III below.The end points of the technical solutions come out after combining the data in TABLE III with TABLE II and weighted calculating, shown TABLE IV below.

TABLE II. TECHNICAL EVALUATION INDEX WEIGHTS ALLOCATION TABLE

\begin{tabular}{|c|c|c|c|c|c|c|c|c|}
\hline Index & \multicolumn{2}{|c|}{$\begin{array}{l}\text { Allowable } \\
\text { stress }\end{array}$} & \multicolumn{2}{|c|}{$\begin{array}{l}\text { High temperature } \\
\text { performance }\end{array}$} & \multicolumn{2}{|c|}{$\begin{array}{c}\text { Plastic } \\
\text { deformation }\end{array}$} & \multicolumn{2}{|c|}{$\begin{array}{c}\text { Welding } \\
\text { performance }\end{array}$} \\
\hline Weights & 0.288 & & 0.147 & 0.226 & \multicolumn{2}{|c|}{0.102} & & 0.237 \\
\hline \multicolumn{9}{|c|}{ TABLE III. } \\
\hline \multicolumn{2}{|c|}{ Solution \Index } & $\begin{array}{l}\text { Allowable } \\
\text { stress }\end{array}$ & $\begin{array}{l}\text { Material } \\
\text { thickness }\end{array}$ & \multicolumn{2}{|c|}{$\begin{array}{l}\text { High temperature } \\
\text { performance }\end{array}$} & \multicolumn{2}{|c|}{$\begin{array}{c}\text { Plastic } \\
\text { deformation }\end{array}$} & $\begin{array}{c}\text { Welding } \\
\text { perform } \\
\text { ance }\end{array}$ \\
\hline SA-38 & & 98.67 & 95.33 & 98.7 & & 73 & & 66.25 \\
\hline 12Cr2I & & 87.67 & 93.67 & 92.00 & & 65 & & 58.75 \\
\hline $12 \mathrm{Cr} 1$ & & 85.33 & 87.33 & 81.50 & & 89 & & 88.00 \\
\hline $12 \mathrm{Cr} 2$ & & 64.33 & 62.00 & 54.25 & & 80.6 & & 83.00 \\
\hline
\end{tabular}

TABLE IV. EXPERT SCORING RESULTS TABLE AFTER WEIGHTED CALCULATED FOR TECHNICAL EVALUATION

\begin{tabular}{cccccrc}
\hline $\begin{array}{c}\text { Solution } \\
\text { Index } \\
\text { (Weights) }\end{array}$ & $\begin{array}{c}\text { Allowable } \\
\text { stress (0.288) }\end{array}$ & $\begin{array}{c}\text { Material } \\
\text { thickness } \\
(0.147)\end{array}$ & $\begin{array}{c}\text { High } \\
\text { temperature } \\
\text { performance } \\
(0.226)\end{array}$ & $\begin{array}{c}\text { Plastic } \\
\text { deformation } \\
(0.102)\end{array}$ & $\begin{array}{c}\text { Welding } \\
\text { performa } \\
\text { nce }(0.237)\end{array}$ & $\begin{array}{c}\text { Total } \\
\text { points }\end{array}$ \\
\hline SA-387Gr91 & 98.67 & 95.33 & 98.75 & 73.67 & 66.25 & 87.96 \\
12Cr2Mo1V & 87.67 & 93.67 & 92.00 & 65.33 & 58.75 & 80.40 \\
12Cr1MoV & 85.33 & 87.33 & 81.50 & 89.33 & 88.00 & 85.80 \\
12Cr2Mo1 & 64.33 & 62.00 & 54.25 & 80.67 & 83.00 & 67.80 \\
\hline
\end{tabular}

The results of the analysis and comparison for technical solutions can be seen from table 4. SA$387 \mathrm{Gr} 91$ gains the highest score, 12Cr2Mo1 gains the lowest score.

\section{B. Economic analysis and comparison}

The cost structure analysis should be carried out at first before economic analysis and comparison in order to find out the cost difference between different technical solutions. As long as calculating and comparing the total different cost items, the objective of the comparison with solutions will be achieved[5].After analysis, total cost (TC) can consist of material cost (MC), 
material processing cost (MPC), technology test cost (TTC), cold molding cost (RC), welding cost (WC), repair cost (FC).

After the cost structure is established, it is necessary to study the cost items of cost structure and find the cost calculation method.

(1)Material cost is the purchasing price of materials.

(2)Material processing cost refers to the cost of batch grinding of steel plate surface or making the forging blank process into finished products, so to the steel plates:

$$
\mathrm{MPC}=\mathrm{Pm} \times \mathrm{S}
$$

Pm refers to price of unit area for batch grinding (RMB/m2),S refers to square of total surface area of the steel plates (m2);To the forgings:

$$
\mathrm{MPC}=\mathrm{P} 1 \times \pi \mathrm{D}
$$

(3)The cost of welding procedure qualification is the main part of the technique test cost, the worse the welding performance of material is, the higher the test cost produced by the welding materials.

$$
\mathrm{TTC}=\mathrm{Q} \times \mathrm{Pt}+\mathrm{M} \times \mathrm{PC}
$$

$\mathrm{Q}$ refers to the times of test, Pt refers to the cost of each test (RMB),M refers to the total weight of materials for the test, Pc refers to the unit price of the materials for the test $(\mathrm{RMB} / \mathrm{Kg})$.

(4)Cold molding cost is for the technical solution that steel plates are the main materials for shells, SA-387Gr91and 12Cr2Mo1V have this part of costs.

$$
\mathrm{RC}=\mathrm{Pr} \times \mathrm{Ms}
$$

Pr refers to the cost of rolling the plates to the finished product per unit weight of steel plates $(\mathrm{RMB} / \mathrm{t}), \mathrm{Ms}$ refers to the total weight of steel plates (t).

(5)Welding costs consist of the costs of welding materials and labor costs, the costs of welding materials refer to the total costs of welding materials consumed in the welding process to complete the longitudinal and ring welding seams, labor costs refer to the total labor costs consumed in the welding process to complete the longitudinal and ring seam welding.

$$
\mathrm{WC}=\Sigma \mathrm{Pi} \times \mathrm{Li} \times \mathrm{Ci}+\Sigma \mathrm{Phi} \times \mathrm{Hi}
$$

Pi refers to the unit price of one welding material which used in the welding process ( $\mathrm{RMB} / \mathrm{Kg})$, $\mathrm{Li}$ refers to the length of the welding seam for this welding material (m), Ci refers to the quota calculation coefficient for this welding material consumed in the welding seam $(\mathrm{Kg} / \mathrm{m})$, Phi refers to the unit price of labor cost for a kind of welding worker (RMB/h),Hi refers to the total time for this welding worker to weld (h).

(6)Repair cost refers to the loss of the cost to repair due to quality problems in the manufacturing process. Due to the lack of direct calculation of repair costs, it can only be estimated by analogy, according to the welding difficulty degree of different technical solutions, it is necessary to set a repair factor $\rho$ to calculate.

$$
\mathrm{FC}=\rho \times \mathrm{Pj}
$$

Pj refers to the repair cost of past products with the similar product structure (RMB).The calculations on every technical solution need to be carried out separately according to the above formula, the calculation process will be leaved out in this article. By calculation, calculation results are shown the following TABLE V.Seen from TABLE V, the cost of SA-387Gr91 is highest and $12 \mathrm{Cr} 1 \mathrm{MoV}$ is lowest.

\section{Comprehensive comparison and analysis}

After summarizing the results of technical evaluation and economic evaluation, they can be sorted from high to low sequence in the following TABLE VI.From the TABLE VI, we can see that $12 \mathrm{Cr} 1 \mathrm{MoV}$ is better than $12 \mathrm{Cr} 2 \mathrm{Mo} 1$ and $12 \mathrm{Cr} 2 \mathrm{Mo} 1 \mathrm{~V}$ both in the technology and the economy. Therefore, it is easy to find the best solution only by comparing SA-387Gr91 with 12Cr1MoV. According to the solution comparison method, when the gap of two technical solutions in the technical conditions is not very big and can both meet the needs of the project, the economic comparison results will play a critical role in the final selection [4]. From table 5, it can be seen that 
the total cost of $12 \mathrm{Cr} 1 \mathrm{MoV}$ is $38.44 \%$ lower than the total cost of the SA-387Gr91, therefore $12 \mathrm{Cr} 1 \mathrm{MoV}$ has an absolute advantage in economy. From table 4, it can be seen that the evaluation of $12 \mathrm{Cr} 1 \mathrm{MoV}$ is 85.80 , slightly lower than SA-387Gr91 87.96, which is very close. In summary, it can be determined that $12 \mathrm{Cr} 1 \mathrm{MoV}$ is the best solution.

TABLE V. THE COST SUMMARY TABLE FOR FOUR KINDS OF TECHNICAL SOLUTIONS (UNIT:RMB)

\begin{tabular}{|c|c|c|c|c|c|c|c|}
\hline $\begin{array}{c}\text { Solution } \\
\text { Icost }\end{array}$ & MC & MPC & TTC & $\mathrm{RC}$ & WC & $\mathrm{FC}$ & TC \\
\hline SA-387Gr91 & $\begin{array}{c}1334 \\
347\end{array}$ & 149184 & 87947 & $\begin{array}{l}193 \\
221\end{array}$ & $\begin{array}{c}1781 \\
770\end{array}$ & 64979 & 3611448 \\
\hline 12Cr1MoV & $\begin{array}{c}1548 \\
000\end{array}$ & 30000 & 46528 & 0 & 561780 & 36948 & 2223256 \\
\hline 12Cr2Mo1 & $\begin{array}{c}2373 \\
750\end{array}$ & 36000 & 49585 & 0 & 743640 & 53512 & 3256487 \\
\hline 12Cr2Mo1V & 396906 & 0 & 91232 & $\begin{array}{l}353 \\
584\end{array}$ & $\begin{array}{c}2104 \\
480\end{array}$ & $\begin{array}{l}100 \\
653\end{array}$ & 3046855 \\
\hline \multicolumn{8}{|l|}{ TABLE VI. } \\
\hline \multicolumn{2}{|c|}{ Sorting \Solution } & SA-387Gr91 & \multicolumn{2}{|c|}{ 12Cr1MoV } & \multicolumn{2}{|c|}{ 12Cr2Mo1 } & 12Cr2Mo1V \\
\hline \multicolumn{2}{|c|}{$\begin{array}{l}\text { The sequence of } \\
\text { technical evaluation }\end{array}$} & 1 & \multicolumn{2}{|c|}{2} & \multicolumn{2}{|c|}{4} & 3 \\
\hline \multicolumn{2}{|c|}{$\begin{array}{l}\text { The sequence of } \\
\text { economic evaluation }\end{array}$} & 4 & \multicolumn{2}{|c|}{1} & \multicolumn{2}{|c|}{3} & 2 \\
\hline
\end{tabular}

\section{CONCLUSION}

Through the above cases, the use of technical and economic analysis method can help the enterprises to find the best technical solutions, to avoid the errors in the direction of choice. As the above case, it is likely to choose SA-387Gr91 if technical and economic analysis is not carried out, SA-387Gr91 has advantages for its high strength and high temperature performance, the design personnel will tend to choose this solution. But its weakness is also obvious for it is difficult for manufacturing, therefore the disadvantage of manufacturing cost can be enlarged by economic analysis. On the contrary, $12 \mathrm{Cr} 1 \mathrm{MoV}$ will not be the first choice for the design personnel, the allowable stress is very low compared with SA-387Gr91, but through technical analysis, the comprehensive evaluation is just slightly lower than SA-387Gr91.After carried out the economic analysis, the huge advantage in economy is reflected obviously by quantifying. This shows that the use of technical and economic analysis method can effectively solve the practical problems in the enterprise.

\section{ACKNOWLEDGEMENTS}

The authors gratefully acknowledge the financial support of the national natural science foundation, China (No.51435009) and the innovation practice program of Shanghai (IPP 11022IP,P12052).

\section{REFERENCES}

[1] Bayramoglu M,Kobya M,Eyvaz M, et al.Technical and economic analysis of electrocoagulation for the treatment of poultry slaughterhouse wastewater[J].Separation and Purification Technology,2006,51(3): 404-408.

[2] Spence J, Tooth A S. Pressure vessel design: concepts and principles[J]. 1994.

[3] Weitao Liu, Hong Gu, Chun hong Li. The expert evaluation method based on Delphi method [J]. Computer Engineering, 2011,S1:189-191. 
[4] Atkinson A B, Bourguignon F. The comparison of multi-dimensioned distributions of economic status[J]. The Review of Economic Studies, 1982, 49(2): 183-201.

[5] Lotan Y, Gettman M T, Roehrborn C G, et al. Management of ureteral calculi: a cost comparison and decision making analysis[J]. The Journal of urology, 2002, 167(4): 1621-1629. 